\title{
Desvelando ideias socioambientais no Judiciário brasileiro
}

\author{
Unveiling Socio-environmental ideas in Brazilian Judiciary \\ Desvelando ideas socioambientales en el Poder Judicial brasileño
}

Recebido: 14/05/2021 | Revisado: 20/05/2021 | Aceito: 09/06/2021 | Publicado: 11/06/2021

\section{Resumo}

A pesquisa discorre acerca da Responsabilidade Socioambiental com base na Resolução no 198/2014, do Conselho Nacional de Justiça, que disciplina sobre o Planejamento e a Gestão Estratégica no âmbito do Poder Judiciário, período 2015/2020. Objetiva analisar esse documento com foco na Responsabilidade Socioambiental. É uma pesquisa exploratória, balizada na abordagem qualitativa, que conjuga o procedimento bibliográfico e documental. No presente trabalho, são discutidas ideias socioambientais que retratam a Responsabilidade Socioambiental no cenário do Judiciário brasileiro, em uma retrospectiva com o recorte temporal do sexênio 2015/2020, com base nas instituições: Tribunal de Justiça do Acre (TJAC), Tribunal de Justiça do Maranhão (TJMA) e o Conselho Nacional de Justiça (CNJ). Conclui-se que, consoante a resolução esquadrinhada, a Responsabilidade Socioambiental é concebida como um dos atributos de valor do Judiciário para a sociedade. Infere-se ainda, na linha de estudos perquirida, que as ideias socioambientais demarcadas na investigação, criadas ou aperfeiçoada no sexênio 2015/2020, ensejam uma concepção que aponta para a promoção da sustentabilidade.

Palavras-chave: Poder judiciário brasileiro; Resolução no 198/2014 do Conselho Nacional de Justiça; Responsabilidade socioambiental; Gestão socioambiental; Promoção da sustentabilidade.

\begin{abstract}
The research discusses Social-Environmental Responsibility based upon Resolution No. 198/2014, from the National Council of Justice, which regulates Planning and Strategic Management within the scope of the Judicial Branch, period 2015/2020. It intends to analyze this document with a focus on Social and Environmental Responsibility. It is an exploratory research, based on the qualitative approach, which combines the bibliographic and documentary procedure. In this paper, socio-environmental ideas that portray Socio-environmental Responsibility in the Brazilian Judiciary scenario are discussed, in a retrospective with the time frame of the sexennial 2015/2020, centered on the following institutions: Acre Court of Justice (TJAC), Maranhão Court of Justice (TJMA) and the National Council of Justice (CNJ). It is concluded that, according to the studied resolution, Socioenvironmental Responsibility is conceived as one of the attributes of value of the Judiciary to society. It is also inferred, in the investigated line of studies, that the socioenvironmental highlighted ideas in the investigation, created or perfected in the sexennial 2015/2020, give rise to a conception that points to the promotion of sustainability.

Keywords: Brazilian judicial branch; Resolution No. 198/2014 from the National Council of Justice; Socioenvironmental responsibility; Socio-environmental management; Promotion of sustainability.

\section{Resumen}

La investigación discute la Responsabilidad Socioambiental con base en la Resolución No. 198/2014, del Consejo Nacional de Justicia, que regula la Planificación y Gestión Estratégica en el ámbito del Poder Judicial, período 2015/2020. Tiene como objetivo analizar este documento con un enfoque de Responsabilidad Social y Ambiental. Se trata de una investigación exploratoria, basada en el enfoque cualitativo, que combina el procedimiento bibliográfico y documental. En este trabajo se discuten ideas socioambientales que retratan la Responsabilidad Socioambiental en el escenario Judicial brasileño, en una retrospectiva con el marco temporal del sexenio 2015/2020, con base en las instituciones: Tribunal de Justicia de Acre (TJAC), Tribunal de Justicia de Maranhão (TJMA) y el Consejo Nacional de Justicia (CNJ). Se concluye que, según la resolución buscada, la Responsabilidad Social y Ambiental se concibe como uno de los atributos de valor del Poder Judicial para la sociedad. También se infiere, en la línea de estudios investigados, que las ideas socioambientales demarcadas en la investigación, creadas o perfeccionadas en el sexenio 2015/2020, dan lugar a una concepción que apunta a la promoción de la sostenibilidad.
\end{abstract}


Palabras clave: Poder judicial brasileño; Resolución No. 198/2014 del Consejo Nacional de Justicia; Responsabilidad socioambiental; Gestión socioambiental; Promoción de la sostenibilidad.

\section{Introdução}

No cenário atual, as questões ambientais têm se colocado cada vez mais relevantes, inclusive em âmbito internacional, e repercutem em políticas socioambientais implementadas por organizações para promover a sustentabilidade. Dessa forma, vislumbra-se a tendência de instituições inserirem em sua gestão atos que se conciliam com os interesses econômicos, ambientais e sociais.

Nesse quadro, desponta-se essa análise para deslindar a postura perfilhada pelo Judiciário do Brasil, quanto à determinação constitucional que prescreve ao Poder Público o dever de preservar o meio ambiente. Nessa lógica, ao focalizar a investigação na esfera do Judiciário, evidencia-se o fomento, em especial pela atuação do Conselho Nacional de Justiça (CNJ), para que as instituições do sistema de Justiça adotem atos de impacto socioambientais.

Insta asseverar que tanto a missão quanto a visão do Poder Judiciário do Brasil nos termos da Resolução nº 198/2014 do CNJ, a qual disciplina sobre o Planejamento e a Gestão Estratégica no âmbito do Poder Judiciário, período 2015/2020, trabalham os conceitos de efetividade. Também assim, cabe realçar que as ações, práticas, iniciativas, medidas, projetos e programas intentados na órbita do Judiciário e que visam a defesa e/ou preservação do meio ambiente refletem na efetividade da Justiça. Considerando as reflexões externadas, vale elucidar que esse estudo esmiúça a Responsabilidade Socioambiental na abrangência do Judiciário brasileiro, sob o enfoque da Resolução nº 198/2014.

Delimitando-se no recorte temporal 2015/2020, definido na resolução perquirida, a pesquisa se origina da seguinte indagação: No contexto do Judiciário brasileiro quais ideias ilustram a filosofia difundida na Resolução nº 198/2014 do CNJ, no que tange à Responsabilidade Socioambiental?

Sob esse eixo investigativo, objetiva-se analisar a Resolução $n^{\circ}$ 198/2014, com ênfase na Responsabilidade Socioambiental. Nessa linha, buscou-se explorar aludido documento; apontar ideias socioambientais praticadas por instituições do sistema de Justiça brasileiro; e apurar pontos-cerne influentes que indicam a Responsabilidade Socioambiental.

A pesquisa em tela dispõe de pertinência temporal, eis que faz um exame retrospectivo da Responsabilidade Socioambiental em uma interface com a promoção da sustentabilidade, que é um macrodesafio contido no Planejamento Estratégico do Poder Judiciário para o período 2021/2026. Ademais, a pesquisa em pauta explicita relevância social por descortinar ideias detectadas no Judiciário e que privilegiam o alcance social, ambiental e econômico.

Argumenta-se a relevância dessa investigação tendo em vista que a abordagem acadêmica acerca do vetor socioambiental empreendido no Judiciário brasileiro permite desvendar e compartilhar pontos de interesse que podem ser replicados/multiplicados, ou reajustados, em outras realidades, a contribuir com o bem comum. Trata-se de uma pesquisa exploratória, contendo abordagem qualitativa, atrelada ao procedimento bibliográfico-documental.

Nesse sentido, apresenta-se o referido artigo, o qual está esquematizado nas partes aqui especificadas. Inicialmente, são elucidados os fundamentos teóricos que articulam a linha de estudos da investigação. Em seguida, são esclarecidos os procedimentos metodológicos utilizados para cumprir os objetivos da pesquisa. Posteriormente, são discutidos os apontamentos focais da análise deslindada, a fim de, então, serem apresentadas, nas linhas finais desse escrito, as conclusões aferidas em consonância com a apreciação feita. 


\section{Perspectivas Teóricas sobre o Meio Ambiente}

A pesquisa discute acerca da Responsabilidade Socioambiental sob o prisma da Resolução nº 198/2014 (CNJ, 2014). Nesse raciocínio une, sobretudo, preleções de caráter constitucional, conectando linhas teóricas que trabalham os institutos de procedência constitucional relacionado ao meio ambiente.

A princípio, é importante observar a ponderação apontada por Torres (2019):

[...] tem sido crescente a preocupação de organismos internacionais - destaque-se a atuação da Organização das Nações Unidas e suas agências - com a sustentabilidade. Em setembro de 2015, durante a Cúpula de Desenvolvimento Sustentável, no âmbito da Assembleia Geral da ONU, foi divulgada a Agenda 2030, contendo os novos "Objetivos de Desenvolvimento Sustentável (ODS)" a refletir os novos desafios de desenvolvimento.

$[\ldots]$

A Agenda 2030 busca fortalecer a paz universal e a erradicação da pobreza, com a implementação de medidas transformadoras destinadas a direcionar o mundo para um caminho sustentável e resiliente. Trata das três dimensões do desenvolvimento sustentável: a econômica, a social e a ambiental - que em muito se assimila com os objetivos do Estado Social e Democrático de Direito. (Torres, 2019, p. 111, grifo do autor).

Em assim sendo, imprime-se a Figura 1, a qual engloba os ODS.

Figura 1 - Objetivos do Desenvolvimento Sustentável.
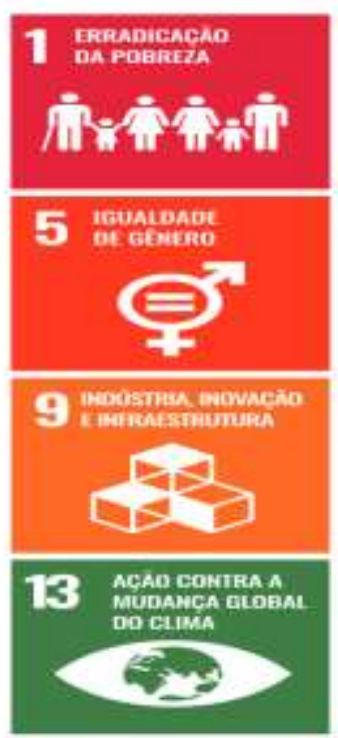

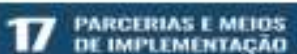
$\&$
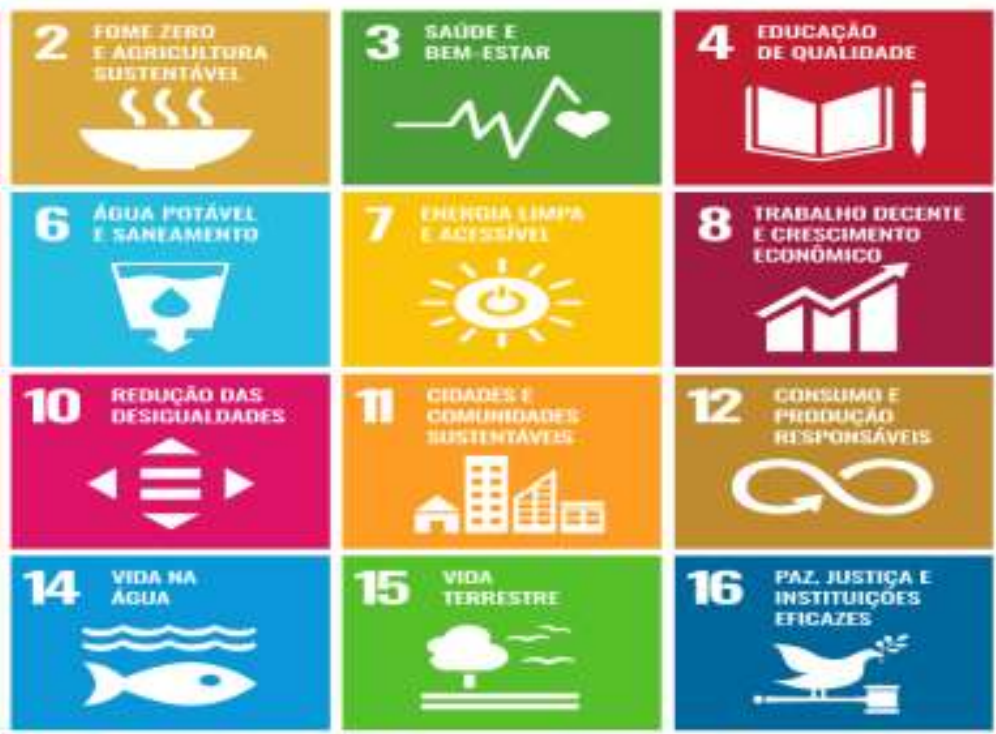

Fonte: Organização das Nações Unidas (2021).

Partindo-se da vasta dimensão que abarca a temática estudada, é condizente focalizar o assunto na esfera brasileira. Desse modo, inicializa-se o debate com a percepção de Lenza (2019, p. 2250), pois ensina que "a análise do constitucionalismo brasileiro nos permite afirmar que foi somente no texto de 1988 que se estabeleceu, de maneira específica e global, a proteção ao meio ambiente". Sob esse horizonte investigativo, denota-se que o tratamento constitucional ao meio ambiente trouxe legitimidade à matéria.

Nessa interlocução, é conveniente desencadear o teor do artigo 170 da Constituição Federal brasileira de 1988, a qual estabelece que: "A ordem econômica, fundada na valorização do trabalho humano e na livre iniciativa, tem por fim assegurar a 
todos existência digna, conforme os ditames da justiça social, observados os seguintes princípios: [...] VI - defesa do meio ambiente; [...]”. (Brasil, 1988, n.p.).

Já Moraes (2017, p. 599) apresenta esta lição: “[...] observe-se que [...] a EC nº 42/03 ampliou a defesa do meio ambiente, prevendo como princípio da ordem econômica a possibilidade de tratamento diferenciado conforme o impacto ambiental dos produtos e serviços e de seus processos de elaboração e prestação". Nesse refletir, Nalini (2010) reluz que é possível o acordo entre o progresso e a preservação do meio ambiente.

Construindo a interação dessas ideias, é consentâneo imprimir que a Constituição Federal do Brasil de 1988 se destaca no universo do constitucionalismo mundial em virtude do capítulo que versa sobre o meio ambiente, encabeçado pelo artigo 225: "Todos têm direito ao meio ambiente ecologicamente equilibrado, bem de uso comum do povo e essencial à sadia qualidade de vida, impondo-se ao poder público e à coletividade o dever de defendê-lo e preservá-lo para as presentes e futuras gerações" (Brasil, 1988, n.p.).

A propósito, a maior influência relativa aos cuidados com o meio ambiente no Brasil compete ao Poder Público (Quintas, 2005). Com fundamento nessa colocação, urge registrar que a Resolução no 198/2014 do CNJ, que dispõe sobre o Planejamento e a Gestão Estratégica no âmbito do Poder Judiciário, ao prescrever a Estratégia Nacional do Poder Judiciário, nos termos do anexo, elenca os atributos de valor para a sociedade, a incluir: Responsabilidade Socioambiental (CNJ, 2014).

Sob esse panorama, denota-se que a interpretação concedida à Responsabilidade Socioambiental pelo Poder Judiciário brasileiro, de acordo com a Resolução no 198/2014 do CNJ, é a de que ela é um atributo de valor para a sociedade.

Intercambiando o embasamento acadêmico desse estudo, traz-se o entendimento de Mendes, Coelho e Branco (2009, p. 1425), posto que concordam acerca desse ponto-chave: "No âmbito constitucional, como assinala a maioria dos juristas, o capítulo do meio ambiente é um dos mais avançados e modernos do constitucionalismo mundial [...]".

A confirmar/reforçar o alicerce acadêmico do trabalho, revela-se a concepção de Bulos (2015, p. 1614), que explica: "O capítulo do meio ambiente da Constituição de 1988 é um dos mais avançados e modernos do constitucionalismo mundial $[\ldots] "$

Nesse caminho, Moraes (2017) acentua que o meio ambiente é um direito humano fundamental de terceira geração. Outrossim, vale escrever essa preleção de Bulos (2015, p. 1614, grifo do autor): "nos últimos decênios, a disciplina constitucional do meio ambiente passou a ser um direito fundamental da pessoa humana, lídimo direito de solidariedade, de terceira geração $[\ldots] "$.

Para corroborar o referencial teórico que erige a linha de investigação do estudo, aborda-se o posicionamento abraçado por Nalini (2010, p. 125), o qual sustenta que: "a sustentabilidade importa em transformação social, sendo conceito integrador e unificante. Propõe a celebração da unidade homem/natureza, na origem e no destino comum e significa um novo paradigma [...]".

Dessa feita, tendo em vista que, com base na Resolução n 198/2014 do CNJ, a Responsabilidade Socioambiental é considerada um atributo de valor do Judiciário brasileiro, depreende-se que as políticas de gestão socioambiental implementadas por instituições do sistema de Justiça tendem em impactar de forma positiva na promoção da sustentabilidade, conciliando-se os interesses sociais, ambientais e econômicos.

Assim sendo, deduz-se que há uma relação entre as políticas de gestão socioambiental e a cultura sustentável do Judiciário, no sentido de que as primeiras instigam hábitos que tendem a ser assimilados na rotina institucional. 


\section{Metodologia}

A pesquisa em tela explana acerca da Responsabilidade Socioambiental sob a perspectiva da Resolução n 198/2014 do CNJ. Dessa maneira, reputa-se a pesquisa como sendo exploratória, lapidada por meio da abordagem de pesquisa qualitativa, esmerada no procedimento bibliográfico e documental.

Nessa exposição de ideias, insta sublinhar o entendimento defendido por Lakatos e Marconi (2010, p. 171), uma vez que, ao conceituarem as pesquisas exploratórias, ancoram que elas têm como fim: “[...] desenvolver hipóteses, aumentar a familiaridade do pesquisador com um ambiente, fato ou fenômeno, para a realização de uma pesquisa futura mais precisa, ou modificar e clarificar conceitos". Como decorrência, é pertinente destacar que a pesquisa é exploratória, já que incute uma aproximação entre pesquisadores e objeto de estudo.

No que concerne à pesquisa qualitativa, sob o ponto de vista de Chizzotti (2009), esse tipo de pesquisa almeja, em regra, proporcionar a elucidação acerca de algum contexto. Nessa senda, verifica-se que a pesquisa em comento é qualitativa, eis que investiga a Resolução n ${ }^{\circ}$ 198/2014 do CNJ, buscando desenredar ideias efetivas que concebem a Responsabilidade Socioambiental como valor institucional do Judiciário.

Quanto ao procedimento de pesquisa bibliográfico, Gil (2009) declara que os aportes acadêmicos de diferentes teóricos sobre um assunto específico consubstancia, em fundamento, a fonte de que se recorre a pesquisa bibliográfica. Nesse viés, a presente pesquisa é reputada como sendo bibliográfica, posto que os estudos estão sedimentados em fontes escritas que fornecem respaldo teórico para cimentar a linha de investigação destrinchada.

No tocante ao procedimento de pesquisa documental, Reis (2018, p. 22) explica que "a pesquisa documental busca obter materiais/documentos que não receberam tratamento analítico [...]" Nesse pensar, Gil (2009, p. 45) argumenta que "[...] a pesquisa documental vale-se de materiais que não recebem ainda um tratamento analítico, ou que ainda podem ser reelaborados de acordo com os objetos da pesquisa". Nessa linha de raciocínio, note-se que a pesquisa emprega o procedimento documental, sobretudo, para examinar a Resolução no 198/2014, uma vez que esta traz o conceito de Responsabilidade Socioambiental sob o aspecto de valor institucional do Judiciário brasileiro (Conselho Nacional de Justiça, 2014).

\section{Resultados e Discussão}

Fica claro o comprometimento constitucional com o tema do meio ambiente no ordenamento jurídico brasileiro. Isso ocorre porque a Constituição Federal do Brasil de 1988 se desponta no universo internacional quando o assunto é o capítulo que trata sobre o meio ambiente, em razão do teor avançado e moderno expresso no seu artigo 225.

Por conta disso, cabe iterar o pensamento de Mendes, Coelho e Branco (2009), os quais esclarecem que no segmento constitucional, em termos mundiais, como pontua parte expressiva dos doutrinadores, o capítulo da Carta Magna de 1988 que discute sobre o meio ambiente é um dos que se sobreleva por conter estes distintivos: Avançado e moderno. Em acréscimo, Bulos (2015) leciona que o capítulo que disserta sobre o meio ambiente na Constituição Federal de 1988 tem dois elementos influentes no que tange ao constitucionalismo mundial, é avançado e moderno.

Nessa linha de pensamento, Torres (2019) explana que as questões que tangenciam a sustentabilidade têm sido objeto de preocupação por organizações internacionais, a enfatizar o papel da Organização das Nações Unidas (ONU). Inclusive, aponta que em 2015 foi difundida a Agenda 2030 com os atuais Objetivos do Desenvolvimento Sustentável (ODS). E ainda assinala que a Agenda 2030 visa consolidar a pacificação global e combater a miséria mediante a efetivação de estratégias convergentes, tendo em mira a sustentabilidade e a resiliência dos países, abrangendo os critérios econômico, social e ambiental. 
Nesse intercâmbio de ideias, é salutar escrever o posicionamento de Lenza (2019), uma vez que acredita que a partir do Texto Constitucional de 1988 fixou-se de forma detalhada a preservação ao meio ambiente. Insta asseverar que Lenza (2019) sublinha que se vislumbra da redação constitucional de 1988 o tratamento de modo integral à conservação do meio ambiente.

Quintas (2005), por seu turno, assevera que na realidade brasileira o Poder Público tem grande capacidade de impactar de maneira positiva no atendimento de questões ligadas ao meio ambiente. Nessa lógica, ressalta-se que o Poder Público tem a incumbência constitucional de defender e preservar o meio ambiente (Brasil, 1988). Em tal refletir, cabe ao Poder Público (Executivo, Legislativo e Judiciário) trabalhar ideias que privilegiem a defesa e a preservação do meio ambiente. Nessa interface, insta reafirmar que no ordenamento jurídico brasileiro a defesa do meio ambiente se consubstancia como um dos princípios da ordem econômica (Brasil, 1988).

No balizamento da investigação, delimitam-se os estudos no entorno do Judiciário, sob a ótica da Resolução ${ }^{\circ}$ 198/2014, que condensa o Planejamento e a Gestão Estratégica no âmbito do Poder Judiciário, período 2015/2020 (Conselho Nacional de Justiça, 2014), para identificar casos práticos que revelam a concepção de Responsabilidade Socioambiental como atributo de valor institucional. A partir desse ponto de ancoragem, desvenda-se a precisão do diálogo que ambicionsia desvelar ideias que exemplificam a Responsabilidade Socioambiental sob a perspectiva de valor institucional do Judiciário brasileiro.

Por isso, a análise deslinda o Tribunal de Justiça do Acre (TJAC), sob o fundamento de que se logrou vencedor, na segunda colocação, com a criação do Projeto Bosque da Justiça, implantado em março de 2018, categoria uso/manejo sustentável dos recursos naturais, na oitava edição do Prêmio Melhores Práticas de Sustentabilidade na Administração Pública - Prêmio A3P (Agenda Ambiental na Administração Pública, 2020). Aliás, "a Agenda Ambiental na Administração Pública (A3P) é um programa do Ministério do Meio Ambiente que objetiva estimular os órgãos públicos do país a implementarem práticas de sustentabilidade [...]”. (MMA, s.d.). Seguindo essa linha de entendimento, demarcam-se os seguintes pontos congregados no projeto em menção, quais sejam:

Componente Ambiental [...] refere-se à equipe técnica: Nesse momento, já se conseguiu a formação da equipe (por enquanto), de três técnicos com formação voltada para as questões ambientais; Levantamento das espécies florestais, espécies da fauna, para realização de atividades de educação ambiental; Existe uma premente necessidade da equipe técnica conhecer outros exemplos de parques ambientais de acordo com a proximidade da nossa biodiversidade e com exemplos de gestão e administração; fortalecer rede de contatos com parceiros com expertise exigida e sensibilização aos parceiros para engajamento ao projeto.

[...] Componente Econômico [...] Elaboração da primeira etapa do projeto, planejamento da infraestrutura e edificações do parque com o objetivo de captar recursos financeiros para conclusão de estudos, bem como das instalações necessárias ao funcionamento do parque.

[...] Componente Social [...] Fortalecer a parceria com as Universidades e os alunos que participarão na elaboração do plano de edificação e disponibilizar todas as condições para a efetivação das atividades. (AGENDA AMBIENTAL NA ADMINISTRAÇÃO PÚBLICA, 2020, n.p., grifo nosso).

Como consequência do reconhecimento desse projeto pelo Ministério do Meio Ambiente, deduz-se que as ações e os atos definidos para efetivação do mesmo têm credibilidade e confiabilidade, a sinalizar apontamentos adequados de preservação ao meio ambiente à luz da determinação constitucional, firmada no artigo 225 da Carta Republicana de 1988. Nessa interface de ideias, o artigo constitucional em alusão legitima o direito ao meio ambiente ecologicamente equilibrado (Brasil, 1988). É oportuno salientar que Torres (2019) articula que, consoante a disciplina constitucional, o direito ao meio ambiente ecologicamente equilibrado é uma garantia para todas as pessoas.

É oportuno salientar também que a Carta Magna de 1988 dispõe que cabe ao Poder Público a atribuição da defesa e preservação do meio ambiente (Brasil, 1988). Vale redizer que Nalini (2010) afirma que a sustentabilidade repercute em mudança na área social. Nesse norte acadêmico, Torres (2019, p. 111) postula que “[...] a adoção de políticas públicas voltadas 
ao desenvolvimento sustentável é medida que urge". Sob esse olhar, denota-se a relevância em empreender ideias bem articuladas que tendam em repercutir na proteção ao meio ambiente. Portanto, o estudo esmiúça essa temática incutindo preocupação com a continuidade da vida.

Prosperando nessa trilha de estudos, a análise deslinda o Tribunal de Justiça do Maranhão (TJMA) pela criação da seguinte política socioambiental:

TJMA Sustentável - A premiação foi instituída pela Resolução No 5/2020, do Tribunal de Justiça e tem a finalidade de reconhecer as iniciativas que promovam a adesão de magistrados, servidores e funcionários terceirizados à Política de Sustentabilidade no âmbito do Poder Judiciário estadual. A iniciativa está em conformidade com a Resolução $\mathrm{N}^{\circ}$ 201/15 do Conselho Nacional de Justiça (CNJ) e o Plano de Logística Sustentável do TJMA. (Brasil, 2020a, n.p.).

Nessa vertente, é cabível informar:

Resultados positivos - O Núcleo de Gestão Socioambiental do TJMA é presidido pelo desembargador Jorge Rachid Mubárack Maluf, que durante o evento enalteceu os esforços que o Tribunal de Justiça vem envidando ao longo dos anos. Ele ressaltou a economia de quase 25 milhões de copos descartáveis, desde a implantação da política sustentável do TJMA. [...]

O desembargador lembrou de ações como a instituição do Programa de Qualidade de Vida no Trabalho e substituição de lâmpadas por modelos mais econômicos. Sobre o Programa de Gestão de resíduos, frisou que de 2016 a 2019 houve a destinação de $\mathbf{1 4 6}$ mil toneladas de papel, plástico e papelão para cooperativas de reciclagem. Esse trabalho contribuiu para elevação da renda de agentes ambientais (catadores) de $\mathbf{R} \$ \mathbf{3 0 0 , 0 0}$ para R\$ 1.500,00. (Brasil, 2020a, n.p., grifo nosso).

Depreende-se a efetividade do Prêmio TJMA Sustentável ao evidenciar que o mesmo suscitou a economia interna do TJMA, com a melhoria tanto do ambiente de trabalho quanto da sociedade (alcance/contribuição social). Com base nisso, ao averiguar efeitos positivos (efetividade) gerados por ações empreendidas no TJMA e descortinadas no fragmento encimado, consolida-se a opinião de Moraes (2017), pois argumenta que a defesa do meio ambiente dialoga com as concepções do campo da economia. Nesse tecer de ideias, é coerente anotar que: “[...] a longo prazo, portanto, a sustentabilidade do sistema econômico não é possível sem estabilização dos níveis de consumo per capita de acordo com a capacidade de carga do Planeta [...]" (Romeiro, 2008, p.442, grifo do autor).

De mais a mais, em arremate, a análise deslinda o $\mathrm{CNJ}$, ao delinear que no campo da Justiça Federal, observa-se que: "CNJ premia TRF2 com Selo da Justiça em Números - Categoria Ouro" (Brasil, 2018, n.p.). A propósito, vale inscrever que:

Entre as exigências para recebimento do Selo Justiça em Números está ainda a implantação de núcleos socioambientais, conforme previsto na Resolução CNJ n. 201, de 2015, que determina aos órgãos do Poder Judiciário a implementação do Plano de Logística Sustentável (PLS) para reduzir o impacto ambiental de suas atividades. (Brasil, 2018, n.p., grifo nosso).

$\mathrm{Na}$ atual conjuntura, o referido prêmio foi convertido para o CNJ de Qualidade, o qual continua incentivando, dentre outros indicadores, a sustentabilidade no âmbito do Judiciário brasileiro. Nessa interação de ideias, é condizente assentar que:

O Tribunal Regional Federal da $4^{\mathrm{a}}$ Região (TRF4) foi agraciado com o troféu Ouro da categoria Justiça Federal no Prêmio CNJ de Qualidade 2020. [...]. Na categoria Prata, foram laureados os TRFs da $1^{\text {a }}$ e da $5^{\text {a }}$ Regiões. [...] a análise levou em conta temáticas como sustentabilidade, celeridade, acessibilidade, produtividade, confiabilidade de dados, informatização e reflete de forma sistemática e objetiva os resultados dos Tribunais nos anos de 2019 e 2020 [...]. (Brasil, 2020b, n.p., grifo nosso).

Levantam-se os aludidos prêmios cunhados pelo CNJ - os quais se evidenciam pelo amplo alcance para o fomento da sustentabilidade - como ideias caracterizadoras da Responsabilidade Socioambiental nos termos da resolução estudada. Esse 
diagnóstico traduz a envergadura do $\mathrm{CNJ}$ em face do Poder Judiciário do Brasil, por se tratar de instituição pública que impulsiona, em dimensões expressivas, a melhor gestão dos tribunais brasileiros, a englobar a área da sustentabilidade.

Ratificando o teor desse estudo, é pertinente reiterar a visão de Moraes (2017), pois enfatiza que o meio ambiente é um direito humano fundamental de terceira geração. Sob esse prisma, Bulos (2015) elucida que o meio ambiente configura direito fundamental de terceira geração da pessoa humana.

Nesse sentido, delibera-se acerca da Responsabilidade Socioambiental em conformidade com a Resolução $n^{\circ}$ 198/2014, do CNJ, a organizar no Quadro 1 as constatações centrais desvencilhadas na pesquisa em tela.

Quadro 1 - Panorama das ideias socioambientais - Planejamento e Gestão Estratégica - Poder Judiciário - 2015/2020.

\begin{tabular}{|c|c|}
\hline $\begin{array}{c}\text { Ideias socioambientais e pontos de evidência que apontam a } \\
\text { Responsabilidade Socioambiental }\end{array}$ & Instituições cenário \\
\hline Projeto Bosque da Justiça & TJAC \\
\hline Reconhecimento em premiação (Ministério do Meio Ambiente) & TJMA \\
\hline Prêmio TJMA Sustentável & \\
\hline Prêtividade das ações empreendidas & \\
Prêmio CNJ de Qualidade & CNJ \\
\hline Amplo alcance para o estímulo da sustentabilidade nos tribunais brasileiros & \\
\hline
\end{tabular}

Fonte: Autores (2021).

Sendo assim, reduz-se que o exame aqui realizado esmiúça a Resolução no 198/2014 do CNJ, a inferir que a Responsabilidade Socioambiental é interpretada como um dos atributos de valor do Judiciário para a sociedade. Esse estudo espelha a união entre o pensamento jurídico e a noção de administração. Isso acontece porque a Resolução nº 198/2014 do CNJ confere à Responsabilidade Socioambiental aspecto administrativo: atributo de valor institucional, relativo à gestão socioambiental do Judiciário brasileiro.

Nessa conexão de saberes dialogados, as ideias/políticas de gestão socioambiental do Judiciário balizadas nessa pesquisa, com fundamento no dever constitucional estipulado no artigo 225 (defender e preservar o meio ambiente), com vistas no conceito de Responsabilidade Socioambiental disposto na Resolução nº 198/2014 do CNJ, testificam a Responsabilidade Socioambiental das instituições cenário dessa pesquisa.

Pondera-se que as ideias desveladas na análise exploratória de cunho qualitativo, com nuance bibliográficodocumental, tendem em acarretar a promoção da sustentabilidade, a qual é um dos macrodesafios relacionados no Planejamento Estratégico do Poder Judiciário atinente ao período 2021/2026 (Conselho Nacional de Justiça, 2020). No que tange a essa questão, explicita-se a Figura 2. 
Figura 2 - Mapa Estratégico dinamizado com os Objetivos de Desenvolvimento Sustentável da Agenda 2030.

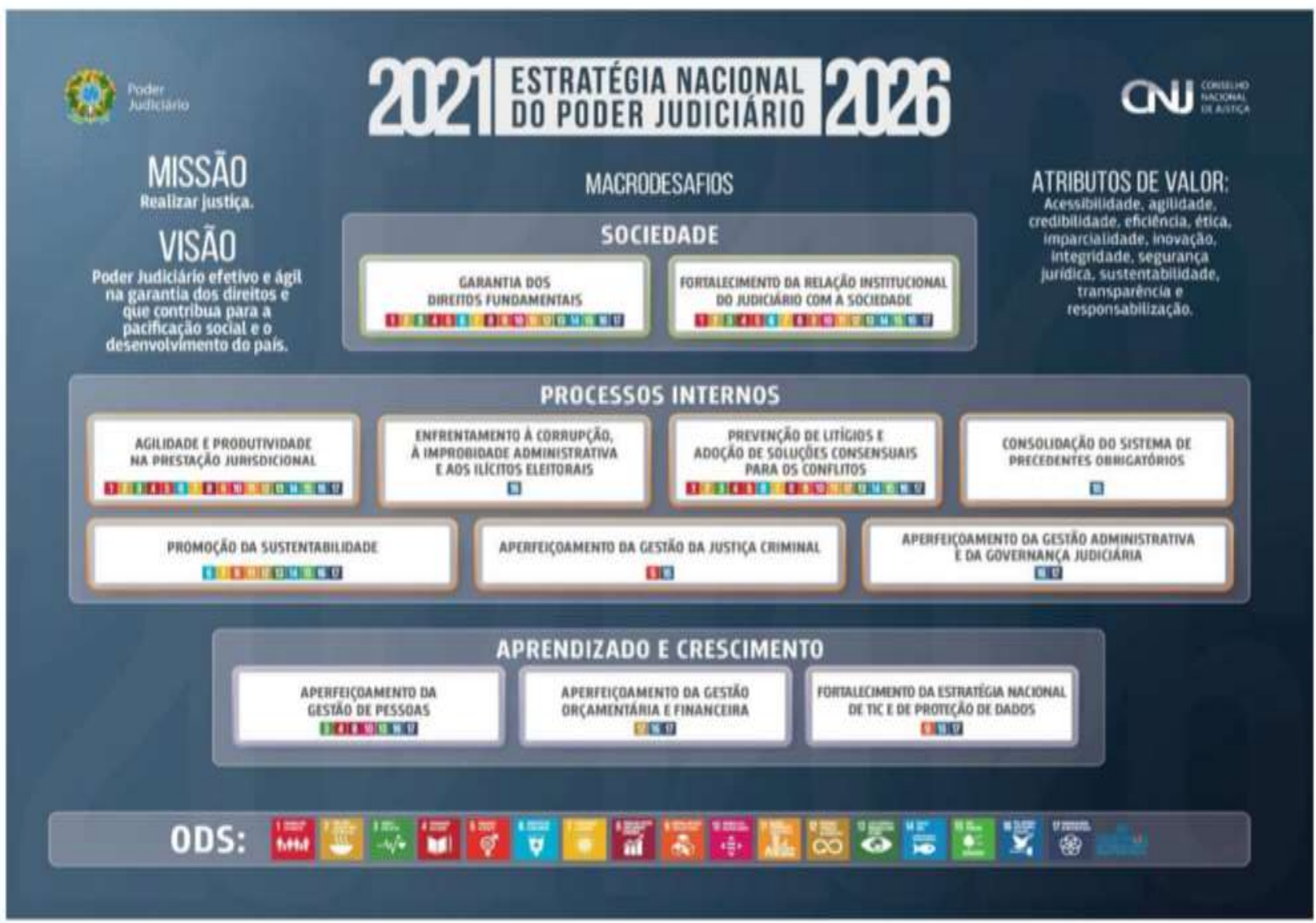

Fonte: Conselho Nacional de Justiça (2020).

Dessa forma, a investigação em tela faz um estudo retrospectivo acerca do valor institucional da Responsabilidade Socioambiental no viés do planejamento estratégico nacional do Judiciário, período 2015/2020, com vistas na projeção futura da promoção da sustentabilidade, a qual é categorizada no planejamento estratégico nacional do Judiciário, sexênio 2021/2026, como um macrodesafio para ser superado. À vista do exposto, infere-se que a pauta do meio ambiente perpassa as atividades cotidianas do Judiciário, a reverberar tendência contemporânea dessa cultura institucional.

\section{Conclusão}

A pesquisa apresenta a Responsabilidade Socioambiental sob o olhar da Resolução no 198/2014, do CNJ, que consolida o Planejamento e a Gestão Estratégica no âmbito do Poder Judiciário, período 2015/2020. Salienta-se que no Brasil a defesa do meio ambiente é um dos princípios da ordem econômica. Nesse caminho, espraiam-se fundamentos basilares acerca da temática que versa sobre o meio ambiente, matéria de procedência constitucional insculpida no artigo 225, que exemplifica um dos capítulos mais avançados e modernos na dimensão do constitucionalismo mundial. Ressalta-se que o meio ambiente é consagrado como direito humano fundamental de terceira geração. Desaguam-se os estudos no balizamento de ideias socioambientais identificadas no Judiciário e que traduzem alinhamento aos preceitos da Constituição Federal de 1988, quanto à preservação ao meio ambiente, bem como evidenciam a Responsabilidade Socioambiental nos termos contidos na Resolução n $198 / 2014$ do CNJ, na qual ela tem o aspecto de atributo de valor para a sociedade.

Nesse amadurecer de ideias, desvenda-se, para essa linha investigativa, o conceito de Responsabilidade Socioambiental nas instituições cenário desta pesquisa: TJAC, TJMA e CNJ, as quais reforçam a possibilidade de acordar 
interesses econômicos, ambientais e sociais. Desenredam-se estas ideias caracterizadoras da filosofia difundida na resolução perscrutada no tocante à Responsabilidade Socioambiental: Projeto Bosque da Justiça (de forma que a premiação dele o evidencia como um ponto influente para esse estudo); Prêmio TJMA Sustentável (de maneira que os efeitos positivos acarretados por ele o ressaltam nessa análise); Prêmio Selo Justiça em Números e Prêmio CNJ de Qualidade (de modo que o amplo alcance dos mesmos em impactar na sustentabilidade - denotado no reconhecimento concedido na categorização da Justiça Federal, à Justiça Federal da $2^{a}$ Região, à Justiça Federal da $4^{a}$ Região, à Justiça Federal da $1^{a}$ Região e à Justiça Federal da $5^{\text {a }}$ Região - os levantam para essa pesquisa).

Afinal, as ideias socioambientais desveladas nesse escrito tendem em assinalar uma concepção referente à promoção da sustentabilidade, que é definida como um dos macrodesafios da Estratégia Nacional do Poder Judiciário para o sexênio 2021/2026.

Acredita-se que o descortinamento do conteúdo que permeia essa análise exploratória de cunho qualitativo e matiz bibliográfica-documental pode ser incrementado para desvelar outras ideias ensejadoras da sustentabilidade, observando-se trilha metodológica e conjugação pedagógica para executar essa caminhada acadêmica.

Como ponto de articulação para a continuidade dos estudos aponta-se a evidência de fatores influentes para o fomento da sustentabilidade com foco no planejamento estratégico do Judiciário previsto para o período 2021/2026.

\section{Referências}

A3P. Agenda Ambiental na Administração Pública. (2020). Resultado do $8^{\circ}$ prêmio melhores práticas A3P/2020. Prêmio. http://a3p.mma.gov.br/8o-premioa3p-2020/.

Brasil. (1988). Constituição da República Federativa do Brasil [de] 1988. Brasília, DF: Senado Federal/Centro Gráfico.

Brasil. Tribunal de Justiça do Maranhão. (2020a). Meio ambiente/Corregedoria e unidades de $1^{\circ}$ grau recebem prêmio de sustentabilidade. Notícias. https://www.tjma.jus.br/midia/cgj/noticia/433525.

Brasil. Tribunal Regional Federal (2. Região). (2018). CNJ premia TRF2 com Selo da Justiça em Números - Categoria Ouro. Notícias. https://www10.trf2.jus.br/portal/cnj-premia-tribunais-com-selo-justica-em-numeros/.

Brasil. Tribunal Regional Federal (4. Região). (2020b). TRF4 recebe troféu ouro no Prêmio CNJ de Qualidade 2020. Notícias https://www.trf4.jus.br/trf4/controlador.php?acao=noticia_visualizar\&id_noticia=15593.

Bulos, U. L. (2015). Curso de Direito constitucional. (9a ed.), Saraiva.

Chizzotti, A. (2009). Pesquisa em Ciências Humanas e Sociais. Cortez.

Gil, A. C. (2009). Como elaborar projetos de pesquisa. Atlas.

CNJ. Conselho Nacional de Justiça. (2014). Atos administrativos. Resolução $n^{\circ} 198$ de 01/07/2014. Dispõe sobre o Planejamento e a Gestão Estratégica no âmbito do Poder Judiciário e dá outras providências. https://atos.cnj.jus.br/atos/detalhar/2029.

CNJ. Conselho Nacional de Justiça. (2020). Atos administrativos. Resolução $n^{o} 325$, de 29 de junho de 2020. Dispõe sobre a Estratégia Nacional do Poder Judiciário 2021-2026 e dá outras providências. https://atos.cnj.jus.br/files/original182343202006305efb832f79875.pdf.

Lakatos, E. M., \& Marconi, M. de A. (2010). Fundamentos de metodologia científica. Atlas.

Lenza, P. (2019). Direito constitucional esquematizado. (23a ed.), Saraiva Educação.

Mendes, G. F., Coelho, I. M., \& Branco, P. G. G. (2009). Curso de Direito constitucional. (4a ed.), Saraiva.

MMA - Ministério do Meio Ambiente. A3P. Agenda Ambiental na Administração Pública. (s.d.). Sobre A3P. O que é? http://a3p.mma.gov.br/o-que-e/.

Moraes, A. de. (2017). Direito constitucional. (33a ed.), Atlas.

Nalini, J. R. (2010). Ética ambiental. Millennium Editora.

ONU. Organização das Nações Unidas. (2021). Objetivos de desenvolvimento sustentável. https://brasil.un.org/pt-br/sdgs.

Quintas, J. S. (2005). Introdução à Gestão pública. IBAMA.

Reis, C. R. N. (2018). Metodologia da pesquisa em educação. UEMAnet. 
Research, Society and Development, v. 10, n. 7, e31710716097, 2021

(CC BY 4.0) | ISSN 2525-3409 | DOI: http://dx.doi.org/10.33448/rsd-v10i7.16097

Romeiro, A. (2008). Economia ecológica. Instituto Socioambiental, Almanaque Brasil Socioambiental. ISA.

Torres, N. S. F. S. (2019). Desenvolvimento sustentável no Estado democrático de direito: atendimento à agenda 2030 da ONU por meio da regularização fundiária urbana. Revista da Seção Judiciária do Rio de Janeiro, 23(46), 107-136. http://revistaauditorium.jfrj.jus.br/index.php/revistasjrj/article/view/245. 